\title{
GT2013-94618
}

\section{NUMERICAL AND EXPERIMENTAL STUDY OF ETHANOL COMBUSTION IN AN INDUSTRIAL GAS TURBINE}

\author{
Joost L.H.P. Sallevelt \\ Department of Energy Technology \\ University of Twente \\ 7522 NB Enschede \\ The Netherlands \\ Email: j.I.h.p.sallevelt@utwente.nl
}

\author{
Artur K. Pozarlik \\ Gerrit Brem \\ Department of Energy Technology \\ University of Twente \\ 7522 NB Enschede \\ The Netherlands
}

\author{
Martin Beran \\ Lars-Uno Axelsson \\ OPRA Turbines \\ 7554 TS Hengelo \\ The Netherlands
}

\section{ABSTRACT}

The application of ethanol as a biomass-derived fuel in OPRA's 2 MWe class OP16 radial gas turbine has been studied both numerically and experimentally.

For the experimental investigation a modified OP16 gas turbine combustor has been used. This reverse-flow tubular combustor is a diffusion type combustor suitable for both conventional and non-conventional fuels. Two series of ethanol burning experiments have been conducted at atmospheric pressure with a thermal input ranging from 16 to $72 \mathrm{~kW}$. Exhaust gas temperature and emissions $\left(\mathrm{CO}, \mathrm{CO}_{2}, \mathrm{O}_{2}, \mathrm{NO}_{\mathrm{x}}\right)$ were measured at various fuel flow rates while keeping the air flow rate and air temperature constant. In addition, the temperature profile of the combustor liner has been determined by applying thermochromic paint.

CFD simulations have been performed in Ansys Fluent for four different operating conditions considered in the experiments. The simulations are based on a 3D RANS code. Fuel droplets representing the fuel spray are tracked throughout the domain while they interact with the gas phase. A temperature profile based on measurements has been prescribed on the liner to account for heat transfer through the flame tube wall. Detailed combustion chemistry is included by using the steady laminar flamelet model.

In general, the predicted temperatures and levels of $\mathrm{CO}_{2}$ and $\mathrm{O}_{2}$ are in reasonable agreement with the experimental results.

\footnotetext{
*Address all correspondence to this author.
}

However, significant deviations are observed between the calculated and measured exhaust gas temperatures and $\mathrm{O}_{2}$ levels in the higher load cases. Also, the comparison pointed out that the CFD model needs to be improved regarding the prediction of the pollutants $\mathrm{CO}$ and $\mathrm{NO}_{\mathrm{x}}$. Finally, the evaporation rate of the fuel droplets may be underestimated in the current simulations. Additional tests have to be performed for further validation.

\section{NOMENCLATURE}

$D_{p} \quad$ diameter of the prefilmer [m]

$F \quad$ cumulative volume fraction

$U_{a} \quad$ air velocity $[\mathrm{m} / \mathrm{s}]$

$\lambda_{\text {ev }} \quad$ evaporation constant

$A L R \quad$ air-to-liquid mass ratio $\left[\mathrm{m}^{2} / \mathrm{s}\right]$

Oh Ohnesorge number

$S M D$ Sauter mean diameter

St Stokes number [m]

$V M D \quad$ Volume mean diameter

We Weber number

$\mu_{f} \quad$ dynamic viscosity of the fuel

$\mu_{p} \quad$ dynamic viscosity of the droplet

$\bar{d} \quad$ characteristic droplet diameter

$[\mathrm{kg} / \mathrm{ms}]$

$[\mathrm{kg} / \mathrm{ms}]$

$\rho_{a} \quad$ air density

$\rho_{f} \quad$ fuel density

$\left[\mathrm{kg} / \mathrm{m}^{3}\right]$

$\left[\mathrm{kg} / \mathrm{m}^{3}\right]$

$\rho_{g} \quad$ gas density $\quad\left[\mathrm{kg} / \mathrm{m}^{3}\right]$

]

]

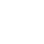


surface tension

$\left[\mathrm{kg} / \mathrm{m}^{3}\right]$

characteristic eddy life time

$[\mathrm{N} / \mathrm{m}]$

$\tau_{k}$

$\tau_{p}$

$d_{p}$

$d_{p, 0}$

$q$

$u_{r}$ particle relaxation time

droplet diameter

initial droplet diameter

droplet size spread parameter

velocity of the droplet relative to the gas [s]

[s]

[m]

[m]

$[-]$

$[\mathrm{m} / \mathrm{s}]$

\section{INTRODUCTION}

The growing interest in renewable power and heat production demands for gas turbine combustors with high fuel flexibility. However, the physical and chemical properties of most nonconventional fuels differ significantly from those of fossil fuels. It is therefore important to investigate how the use of such novel fuels affects the quality of combustion. In this study, the application of ethanol as a biomass-derived fuel in OPRA's 2 MWe class OP16 radial gas turbine combustor has been examined both numerically and experimentally.

\section{EXPERIMENTAL METHOD}

Ethanol spray combustion has been studied in a modified OP16 gas turbine combustor mounted in a test rig. This combustor design has been adjusted by simplifying the geometry to be suitable for numerial validation. The most important simplification is the removal of the wall film cooling holes.

A scheme of the test rig and the location of the sensors is shown in Fig. 1. Thermocouples are used to measure the temperature of the injected fuel, the inlet air and the exhaust gases. The pressure sensor in the top left is used to measure the pressure loss in the combustor. Continuous samples were taken from the exhaust gas to measure its composition during the tests. Concentrations of $\mathrm{CO}_{2}$ and $\mathrm{O}_{2}$ have been determined with an ADC 5000 analyzer, oxides of nitrogen with a Thermo Model $42 \mathrm{C}$ and $\mathrm{CO}$ levels with a Thermo Model 48C.

The experimental procedure started by establishing a stable air flow of $75 \mathrm{~g} / \mathrm{s}$ at a constant temperature. After preheating of the setup by burning fuel for at least $15 \mathrm{~min}$, a series of experiments have been performed at atmospheric pressure with a thermal input ranging from 16 to $72 \mathrm{~kW}$. Once steady state conditions were reached at a certain fuel flow rate, all sensor data was logged using data acquisition software and emissions were read from the gas analyzer displays. The experiments were repeated to validate the results obtained in the first series.

In addition, the temperature profile on the combustor liner for the $45 \mathrm{~kW}$ case has been determined by applying thermochromic paint. To assure an adequate sensitivity of the paint to temperature changes, several different types of paint have been applied. The paint colors have been visually inspected to determine the temperature range at each location on the liner surface.

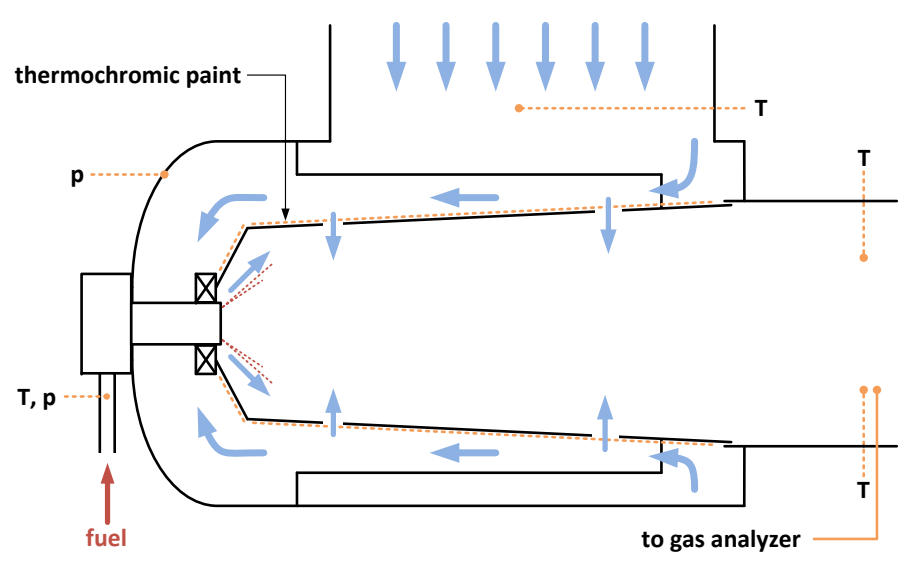

FIGURE 1: SCHEME OF THE TEST RIG AND THE LOCATION OF SENSORS.

The air flow, fuel flow and combustor inlet temperature were measured with an accuracy of $\pm 0.7 \%, \pm 2.4 \%$ and $\pm 1.5 \%$, respectively. The calibration sheet of the exhaust gas thermocouples reports a maximum error of $\pm 0.27 \%$. These thermocouples were not shielded, however, so the actual measurement error will have been higher due to radiation effects.

\section{NUMERICAL MODEL}

The numerical study has been performed using the EulerLagrange approach in Ansys Fluent [1]. In this approach, the fuel spray is considered as a discrete liquid phase travelling in a continuous gas phase. Parcels representing fuel droplets with similar properties are tracked throughout the domain while they interact with the surrounding gas. The RANS equations governing the gas phase are coupled with a non-premixed combustion model to include detailed flame chemistry. The models describing the gas phase, fuel spray and chemical reactions are discussed in the following sections.

\section{Computational domain}

In order to limit the computational cost, a $45^{\circ}$ slice of the combustor geometry is taken as the flow domain. The combustor is not fully rotationally symmetric, however, because the number of circumferentially distributed air admission holes are not always divisible by 8 at all axial locations. Hence, the original geometry had to be modified to allow for the use of periodic boundary conditions in the CFD code. The required symmetry was achieved by changing the number of air admission channels at two locations in the nozzle from 7 to 8 and from 14 to 16, respectively. The total inlet area of these flow passages has been preserved to minimize the influence on the air split in the combustor. A second modification is the extension of the computational domain with $50 \mathrm{~mm}$ to reduce the effect of the outlet 


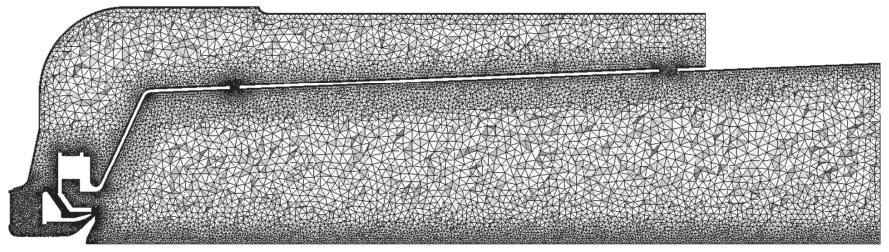

FIGURE 2: FINAL GRID USED FOR THE SIMULATIONS.

boundary condition in the calculations and to get closer to the location of the sensors. The extension of the liner did not lead to any noticeable changes in the flow pattern.

The domain has been spatially discretized using an unstructured tetrahedral grid with two to three layers of prisms at the flow boundaries. Unstructured grids have the advantage of relatively low setup time for complex geometries. In addition, the numerical diffusion in combination with complex flow patterns might be lower due to the random orientation of grid cells relative to the flow. Three grids have been tested to examine grid dependency of the solution. The coarse, medium and fine grid respectively consisted out of 1.45, 2.60 and 3.21 million cells. In all grids, 8 to 12 cells were used across the width of a channel or hole.

Comparison of the velocity and temperature profiles showed that a cell size of $1.3 \%$ of the liner diameter is needed to capture the steep gradients near the walls, whereas twice this cell size is sufficient for the core of the domain. According to this information, a final grid consisting of 2.28 million cells (see Fig. 2) provides the best trade-off between resolution and computation time.

\section{Gas phase}

Chemically reacting turbulent flows are mathematically described by the conservation equations for mass, momentum, species and enthalpy. The density-weighted time-averaged Navier-Stokes equations are solved to obtain the solution of the mean turbulent flow field. These equations are valid under the simplifying assumption of equal diffusion coefficients for all species and unity Lewis number.

The Reynolds stresses and the species and enthalpy turbulent fluxes are closed using the Shear Stress Transport (SST) $k-\omega$ turbulence model. In case of swirling flows, the SST $k-\omega$ model developed by Menter [2] generally shows good performance [3] at modest computational cost. The model combines the advantages of the $k-\omega$ model, which is more robust and accurate in the near-wall region, with the $k-\varepsilon$ model, which is preferred in the far field zones away from the surface. Blending functions are employed to add these two models together.

Heat transfer by nonluminous radiation has been included in the calculations by using the discrete ordinates (DO) model [1].
This type of radiation is due to presence of certain heteropolar gases, mainly carbon dioxide and water vapor. Scattering caused by gas molecules has been neglected, because it does not play a major role in radiative heat transfer [4]. The value of the absorption coefficient depends on the composition of the gas mixture and is computed using the weighted-sum-of-gray-gases model [1]. This model evaluates the local value of the radiation absorption coefficient as function of the local mass fractions of water vapor and carbon dioxide. Luminous radiation depends on the number and size of the solid particles (mainly soot) in the flame. Since soot production in the flame is not modelled, luminous radiation is neglected.

The walls of the combustion chamber participate in the internal heat transfer via both convection and radiation. It is assumed that the absorptivity of the walls is equal to the emissivity, and that the reflected and emitted radiation from the surfaces is fully diffuse.

\section{Fuel spray}

Despite intensive research over the past decades, the atomization process is still not well understood [5]. The physics governing the spray characteristics are very complex and, especially in the dense spray region, are challenging to investigate with current experimental techniques. Most studies therefore start with the atomized spray by imposing a distribution of droplet sizes as an inlet condition for the simulations.

Also in this study, the most complex phenomena taking place in the dense spray region are not captured in the model. Instead, the fuel is injected into the combustor in the form of droplets according to a Rosin-Rammler distribution. Here, the Lagrangian formulation has the advantage that the represention of the imposed distribution is relatively easy, because different properties can be assigned to each droplet.

Once the droplets are injected in the shape of a hollow cone, only secondary breakup needs to be considered. Fig. 3 shows the breakup regime map as presented by Faeth et al. [6]. Here, the grey area denotes the part which is most relevant in this study. The map indicates which breakup mode takes place as function of Weber number and Ohnesorge number defined as:

$$
W e=\frac{\rho_{g} u_{r}^{2} d_{p}}{\sigma} \quad O h=\frac{\mu_{p}}{\sqrt{\rho_{p} d_{p} \sigma}}
$$

where $u_{r}$ is the velocity of the droplet relative to the gas, $d_{p}$ is the droplet diameter, $\sigma$ is the surface tension and the subscripts $g$ and $p$ denote properties of the gas phase and the droplet, respectively.

The Ohnesorge number is the ratio between the viscous forces and surface tension forces. Experimental research has shown that viscous forces are insignificant if $\mathrm{Oh}<0.1$. Taking 


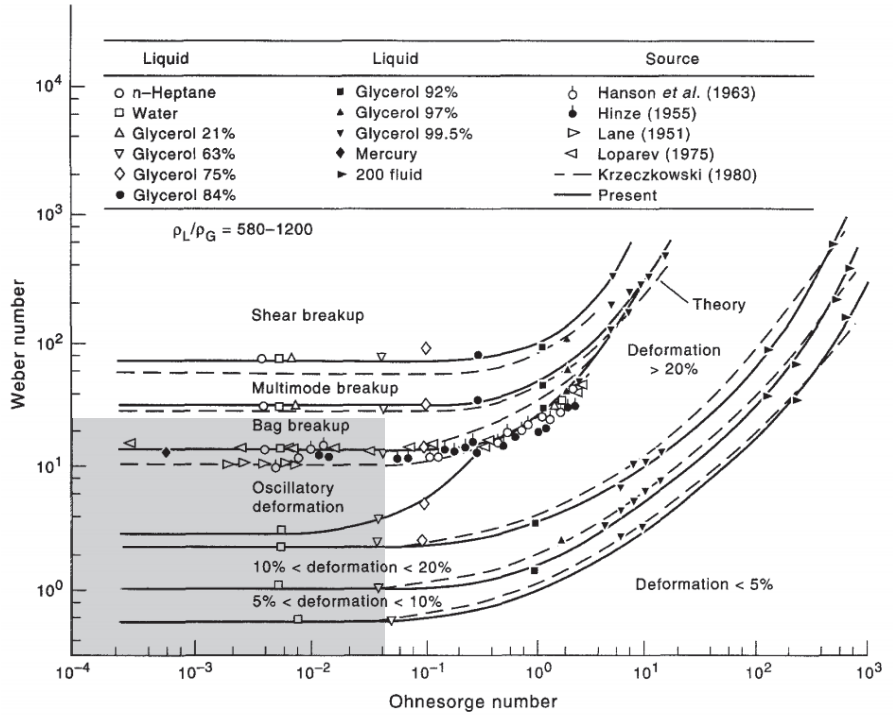

FIGURE 3: BREAKUP REGIME MAP ACCORDING TO FAETH ET AL. [6]. REPRODUCED WITH PERMISSION OF ELSEVIER.

typical values for the properties of air and ethanol near the atomizer, the Ohnesorge number will be approximately 0.04 . This value implies that the breakup process is virtually not influenced by viscous damping of the liquid. The breakup mode is therefore only described by the Weber number, which determines the ratio between the disruptive aerodynamic force and the restorative surface tension force.

From preliminary simulations, it is known that the maximum velocity encountered near the prefilming surface of the nozzle is around $78 \mathrm{~m} / \mathrm{s}$. Assuming that the largest droplets formed during primary breakup are $150 \mu \mathrm{m}$, the maximum Weber number is estimated to be 27. According to the map in Fig. 3, secondary atomization can take place by means of bag breakup. Breakup at these low Weber numbers can be modelled with rather good accuracy using the TAB model developed by O'Rourke and Amsden [1].

The trajectory of a particle or droplet in a carrier fluid is predicted by integrating the force balance over a single dispersed phase particle. In case the particles concern small droplets in a gas turbine combustor, it may be assumed that the density of the droplet is much larger than that of the fluid, that the droplet size is small compared to the turbulence integral length scale and that the effect of shear on droplet motion is negligible [7]. Furthermore, gravity and buoyancy effects can be neglected compared to drag forces. The drag coefficient is calculated from the dynamic drag model [1], in which the drag depends on the flow regime around the droplet and the droplet shape. The random effects of turbulence on particle dispersion are included by using the discrete random walk (or eddy life time) model [1].

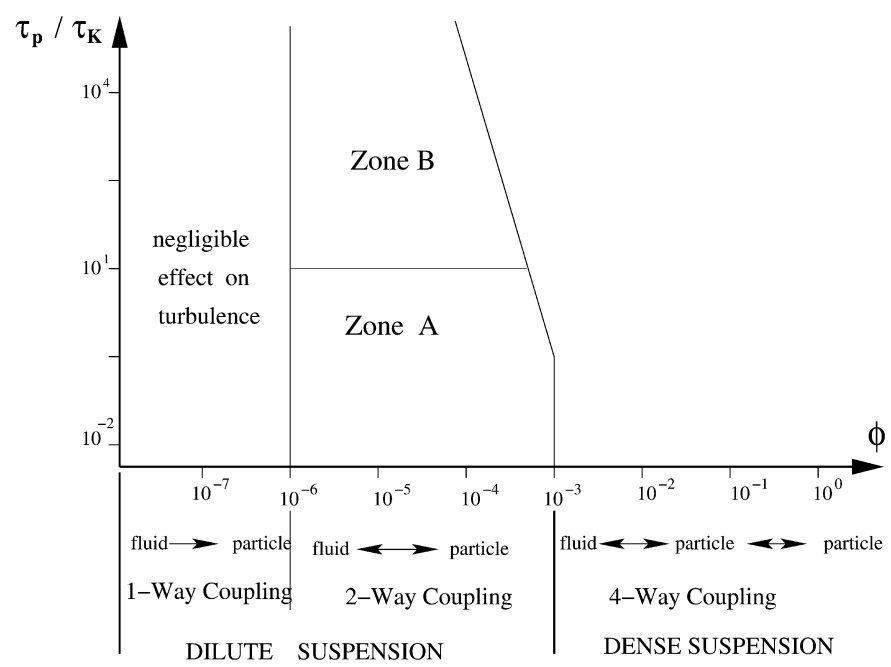

FIGURE 4: CLASSIFICATION MAP OF PARTICLE-LADEN TURBULENT FLOWS ACCORDING TO ELGHOBASHI [8]. REPRODUCED WITH PERMISSION OF SPRINGER.

When modelling a particle-laden flow, it is important to examine the extent of coupling between the discrete and continuous phase [9]. This can be estimated using the classification map proposed by Elghobashi [8]. His map, shown in Fig. 4, indicates the effect of particles on carrier-phase turbulence as function of the particle volume fraction, $\phi$, and the Stokes number, St. Here, the Stokes number is defined as the ratio of the particle relaxation time, $\tau_{p}$, to the characteristic eddy life time, $\tau_{k}$.

In most fuel sprays, the local liquid volume fraction is close to 1 near the orifice of the atomizer and decreases downstream due to desintegration and atomization of the liquid structure [10]. The coupling between the discrete and continuous phase will therefore depend on the portion of the spray that is to be modelled. In the present study, spray calculations start when the liquid is in a dispersed state after primary breakup of the liquid film.

According to a study by Faeth et al. [6], a pressure-atomized spray in still gases after primary breakup can be considered as a dilute environment, where effects of droplet collisions are negligible. This observation is supported by Merci et al. [5], who found that a spray becomes diluted beyond the liquid core, with liquid volume fractions less than about $1 \%$. In the dilute regime droplet collisions are improbable, but a two-way coupling between the phases exists. Therefore, the dispersed spray in the present simulations is modelled using two-way coupling of turbulence and interactions between droplets are neglected.

Several mechanisms cause the droplets to exchange heat and mass with the air along their path. Depending on its temperature, an ethanol droplet can be subjected to heating, evaporation or boiling. Detailed information on the modelling of these processes can be found in the Fluent documentation [1]. In the 


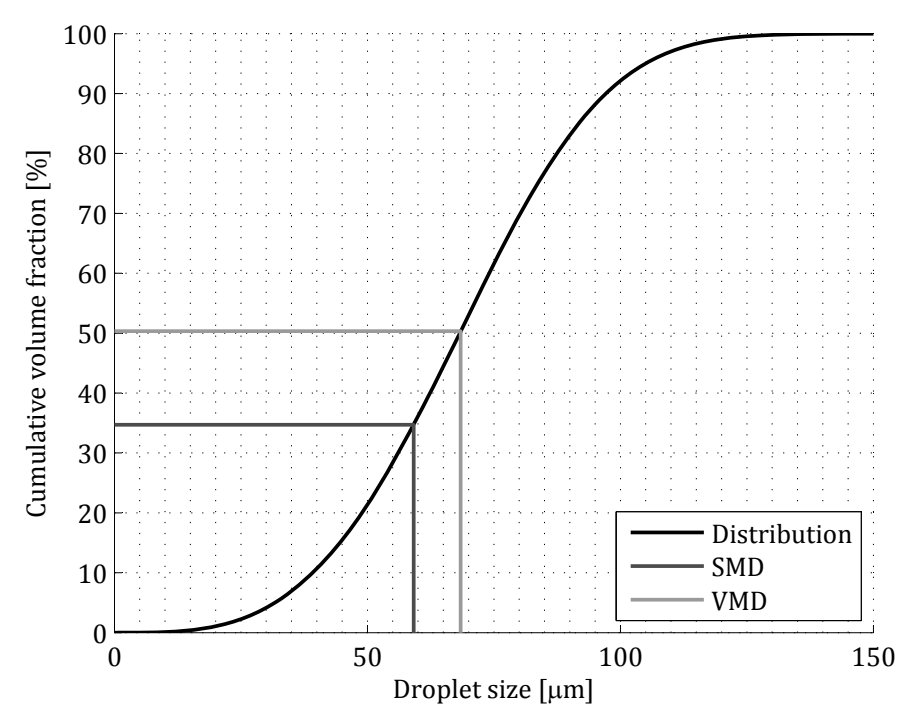

(a) CUMULATIVE DISTRIBUTION CURVE

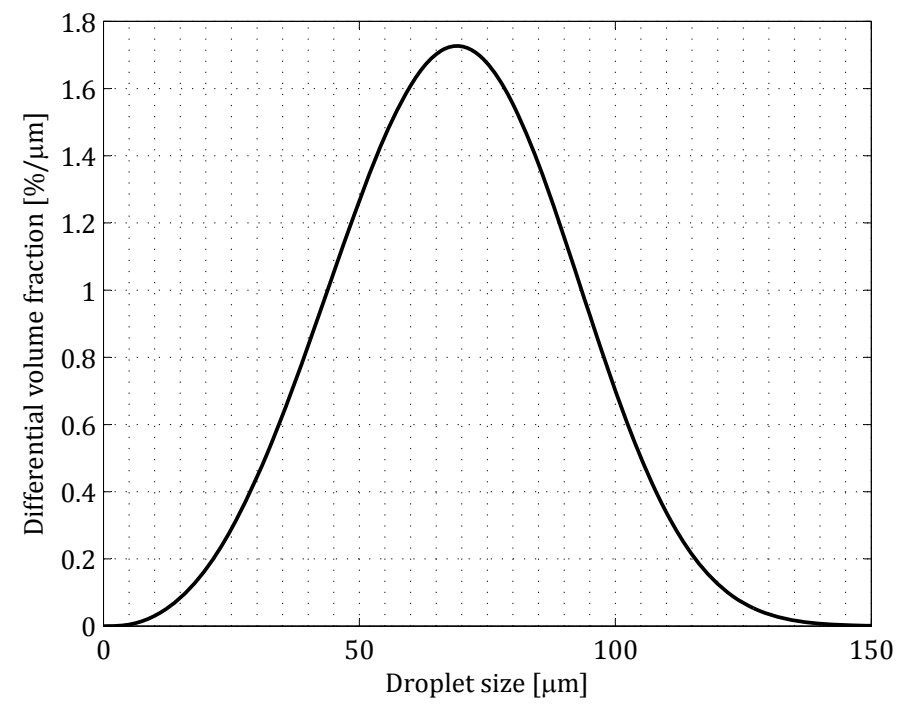

(b) DIFFERENTIAL DISTRIBUTION CURVE

FIGURE 5: CALCULATED DROPLET SIZE DISTRIBUTION CURVES FOR THE ETHANOL SPRAY UNDER BASE CONDITIONS.

evaporation model, the diffusion coefficient of ethanol vapor in air is configured as a function of the bulk temperature. The temperature-dependent diffusion coefficient is calculated according to the method of Wilke and Lee [11]. In case a droplet hits the hot flame tube, it is assumed that the fuel is released instantaneously.

The importance of radiation absorption by fuel droplets relative to convective heat transfer depends primarily on the type of fuel, the temperature of the flame and the droplet size. Faeth [12] states that previous studies have shown that radiation effects are relatively unimportant for droplet sizes representative for most fuel sprays. This conclusion is in accordance with the results of Tseng and Viskanta [13], who studied the influence on heat transfer to n-heptane droplets by radiation. They found that radiation accounts at most for about $15 \%$ of the heat transfer rate by convection for droplets smaller than $100 \mu \mathrm{m}$, so that radiative heating may be ignored for these small sizes.

\section{Droplet size distribution}

Injection of the fuel in the form of droplets requires a definition of the initial droplet size as an input parameter. The droplets formed after primary breakup are not uniform in size, however, because atomization is a random process. To account for these variations, it is assumed that the droplet size obeys a Rosin-Rammler distribution [14]:

$$
1-F=e^{-\left(d_{p} / \bar{d}\right)^{q}}
$$

where $F$ is the volume fraction of the droplets with a diameter smaller than $d_{p}$. The distribution is defined by a characteristic diameter $\bar{d}$ and the spread parameter $q$. Here, $\bar{d}$ is the droplet diameter for which $1-F=e^{-1}$ or, equivalently, $F=0.632$. The parameter $q$ is a measure for the spread in the droplet size.

Experimental data on the droplet size distribution of the spray produced by the prefilming airblast nozzle in the combustor is not available to our best knowledge. Hence, empirical correlations have been used to estimate the two parameters required for defining the spray. A representative value for $\bar{d}$ can be found by first estimating the Sauter mean diameter (SMD). This parameter is defined as the total spray volume divided by the total surface area of all droplets. For prefilming airblast atomizers, Lefebvre [15] proposed the following correlation to estimate the SMD:

$$
\begin{aligned}
S M D & =3.33 \cdot 10^{-3} \frac{\left(\sigma \rho_{f} D_{p}\right)^{0.5}}{\rho_{a} U_{a}}\left(1+\frac{1}{A L R}\right) \\
& +13 \cdot 10^{-3}\left(\frac{\mu_{f}^{2}}{\sigma \rho_{f}}\right)^{0.425} D_{p}{ }^{0.575}\left(1+\frac{1}{A L R}\right)^{2}
\end{aligned}
$$

In Eq. $3, D_{p}$ is the diameter of the prefilmer, $U$ denotes the velocity and ALR is the air-to-liquid mass ratio. The subscripts $f$ and $a$ refer to fuel and air, respectively. Under the assumption that the variation in droplet size can be described by Eq. 2, the SMD is uniquely related to the volume median diameter (VMD). 
The relation between these two representative diameters can be found in Lefebvre et al. [14] and reads:

$$
V M D=S M D(0.693)^{1 / q} \Gamma(1-1 / q)
$$

where $\Gamma$ is the gamma function. The VMD is defined as the droplet diameter for which $50 \%$ of the total liquid volume is in droplets of smaller diameter. Given this definition, the VMD is useful for finding the characteristic droplet diameter $\bar{d}$ in the Rosin-Rammler distribution corresponding to the SMD calculated with Eq. 3. Thus, the parameter $\bar{d}$ must be chosen such, that the distribution curve given by Eq. 2 coincides with $F=0.5$ at the VMD.

A representative value for $q$ is estimated based on experimental data found Lefebvre [15] for an airblast atomizer at different atomizing air velocities. In this source, values of $q$ varying from 3.35 to 3.6 are reported for air speeds of 54.8, 91.4 and 122 $\mathrm{m} / \mathrm{s}$. At an air velocity of $78 \mathrm{~m} / \mathrm{s}$, characteristic for the atomizer used in the ethanol tests, interpolation of the data shows that the spread parameter for a water spray is 3.4. Although the effect of the differences between the properties of water and ethanol is unclear, the reported value is used as an estimation for the spread diameter of the ethanol spray.

Following the method described above, the SMD for the ethanol spray in the tests is calculated to be $59 \mu \mathrm{m}$ using Eq. 3 . If $q$ equals 3.4, Eq. 4 gives a value of $68 \mu \mathrm{m}$ for the VMD. The corresponding setting for $\bar{d}$ in Eq. 2 is then found to be $76 \mu \mathrm{m}$, which results in the droplet size distribution shown in Fig. 5.

\section{Non-premixed combustion modeling}

Solving the species conservation equations for all species involved in detailed chemistry calculations rapidly exceeds computational limits. For this reason, combustion is modeled following the flamelet approach [1]. The general idea is to decompose the combustion problem into two sub-problems: mixing and flame structure. The mixing problem is related to the mixing processes of the fuel and oxidizer streams, and therefore treats all aspects related to the flow field. The flame structure problem involves linking the mixing state to the flame variables, thus describing the combustion process.

Departure from chemical equilibrium due to straining of the flame is characterized by the scalar dissipation rate at the flame location. This parameter essentially accounts for the influence of mixing on the flame structure. In addition, the effect of heat loss or heat gain on the flame temperature has been incorporated by using non-adiabatic flamelets. The actual flame temperature is obtained by correcting the adiabatic flame temperature based on the enthalpy level as calculated from the enthalpy balance equation.
TABLE 1: OPERATING CONDITIONS IN THE FOUR SIMULATED CASES.

\begin{tabular}{lccc}
\hline & $\begin{array}{c}\text { Air flow } \\
{[\mathrm{g} / \mathrm{s}]}\end{array}$ & $\begin{array}{c}\text { Fuel flow } \\
{[\mathrm{g} / \mathrm{s}]}\end{array}$ & $\begin{array}{c}\text { Power } \\
{[\mathrm{kW}]}\end{array}$ \\
\hline Low power & 75 & 1.21 & 35 \\
Base & 75 & 1.55 & 45 \\
High power 1 & 75 & 1.83 & 53 \\
High power 2 & 75 & 2.21 & 64 \\
\hline
\end{tabular}

The chemical reactions have been preprocessed using a reduced mechanism for ethanol oxidation proposed by Roehl and Peters [16]. This mechanism includes 38 species and 228 reactions. The non-adiabatic, steady flamelets have been calculated for different scalar dissipation rates up to the rate at which the flame is extinguished. Average values of the flame variables are then computed and tabulated for different enthalpy levels. The variables stored in the PDF tables are temperature, species mass fraction and density.

Formation of thermal $\mathrm{NO}_{\mathrm{x}}$ is predicted by the extended Zeldovich mechanism [1]. The species concentrations required to calculate the formation rates are obtained from the solution of the combustion model.

\section{Boundary conditions}

A mass flow rate and temperature condition are specified at the inlet. Since the air flow is $75 \mathrm{~g} / \mathrm{s}$ for the full geometry, the setting for the $1 / 8^{\text {th }}$ slice is $9.375 \mathrm{~g} / \mathrm{s}$. The inlet temperature corresponds to the value at which the air leaves the compressor stage in the gas turbine. It is assumed that the turbulence intensity at the inlet is $5 \%$. This parameter can be used to determine the turbulence parameters $k$ and $\omega$. At the outlet, the relative static pressure is set to zero. The fuel flow rate has been varied to make a comparison at different thermal inputs. The operating conditions for the four simulated cases is defined in Tab. 1.

The temperature on the outer surface of the liner at base conditions has been determined experimentally using thermochromic paint. To improve the accuracy, several different types of paint were applied. Visual inspection of the colors resulted in local upper and lower temperature limits. A representative temperature profile for use in CFD is obtained by approximating the mean values of each range indicated by the paint. The normalized temperature limits and the profile for the purpose of CFD are shown in Fig. 6. Although the liner temperature may vary with thermal input, this profile has been imposed on the inner and outer liner surfaces in all simulations to estimate the heat 


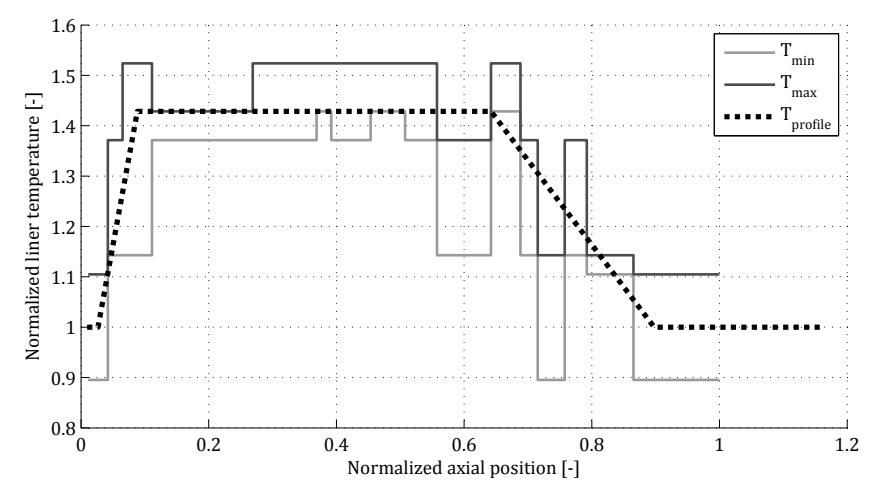

FIGURE 6: NORMALIZED LINER TEMPERATURE LIMITS FROM THE PAINT TEST AND THE PROFILE USED FOR CFD.

loss from the flame tube. An emissivity of 0.7 has been assumed for the (oxidized) inner liner surface and 0.6 was chosen for the remaining surfaces $[4,17]$.

The walls of the outer casing are considered adiabatic to model the thick layer of insulation around the combustor in the test rig. To more closely approximate the open space behind the outlet, a free slip condition has been applied on the extended part of the liner.

\section{Numerical procedure}

The numerical solution presented in this paper has been computed using a pressure-based coupled AMG solver. The coupled algorithm solves the continuity and momentum in a single step, while the remaining equations are solved in a segregated fashion. Next to explicit under-relaxation factors, a pseudo transient technique has been employed as a form of implicit underrelaxation to stabilize the solver while the solution is calculated. The PRESTO! scheme has been selected as the pressure interpolation scheme.

Quantities at cell faces are interpolated from the center values using a second order upwind scheme, except for velocities. For the momentum equation, a first order scheme was used in order to achieve convergence by damping out strong oscillations in the flow. The effect of this setting on the flow field has been evaluated by comparing cold flow simulations. Changing the discretization scheme for only the momentum equation into first order did not lead to significant differences in air split. The difference in air split between the schemes regarding atomization air is $2 \%$, for swirler air $3 \%$, for primary air $0 \%$ and for dilution air $0.4 \%$. The overall flow pattern did not change either, but the velocity profiles measured along the flame tube radius generally showed an underestimation of the recirculation strength. In the primary zone, however, the flow fields predicted by the different methods are in fairly good agreement. Since the phenomena of

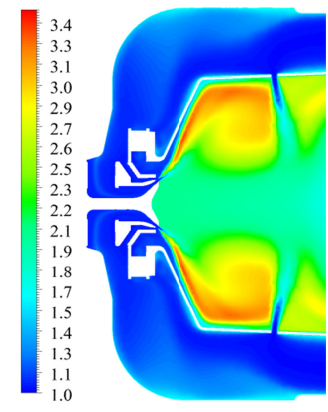

(a) Norm. temperature

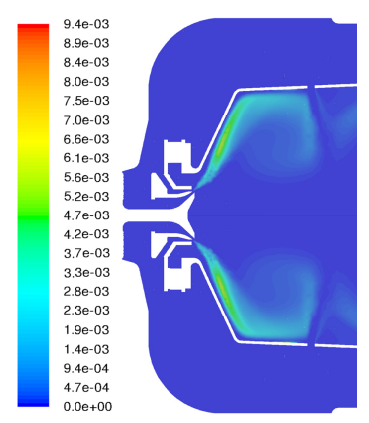

(b) $\mathrm{OH}$ mole fraction
FIGURE 7: NORMALIZED TEMPERATURE FIELD AND OH FIELD IN THE BASE CASE, SHOWN ON A CROSS SECTION OF THE COMBUSTOR.

interest mainly take place in this region, the discretization error of the velocities is considered to be acceptable.

\section{RESULTS AND DISCUSSION}

In this section the results from the ethanol combustion experiments and simulations are reported and compared. Experimental values measured in the two series of experiments have been time-averaged over more than $30 \mathrm{~s}$ with a sampling interval of $0.1 \mathrm{~s}$. The measurement locations are indicated in Fig. 1. Some of the data shown has been normalized by dividing all values by the same constant.

Simulation results have been obtained at the outlet of the computational domain, which is at the same radial position but $40 \mathrm{~mm}$ upstream of the position of the sensors in the test rig. The solution was considered as converged once the residuals were stable for at least 1000 iterations. The normalized overall imbalance of mass and heat in the converged solutions is found to be less than $0.002 \%$ and $2 \%$, respectively. Here, the total mass flow and thermal input are used for normalization.

Figure 7 gives an impression of the flame location by showing the normalized temperature (Fig. 7a) and $\mathrm{OH}$ mole fraction contours (Fig. 7b) inside the combustor under base conditions. Due to the strong recirculation in the primary zone, the flame is forced to the outer region of the flame tube, close to the wall. The liner is cooled by the fresh air from the compressor and a protective air sheet originating from the swirler.

A comparison of the normalized exhaust gas temperatures as function of the thermal power is shown in Fig. 8. In general, the experimental results of both test series show a close match, though a slight deviation is seen around $41 \mathrm{~kW}$. Possibly, this relatively low value measured in the first test series has been caused by insufficient preheating of the combustor. The measurements in test series 1 have been performed from low to high power, which may explain that the first measurement deviates from the 


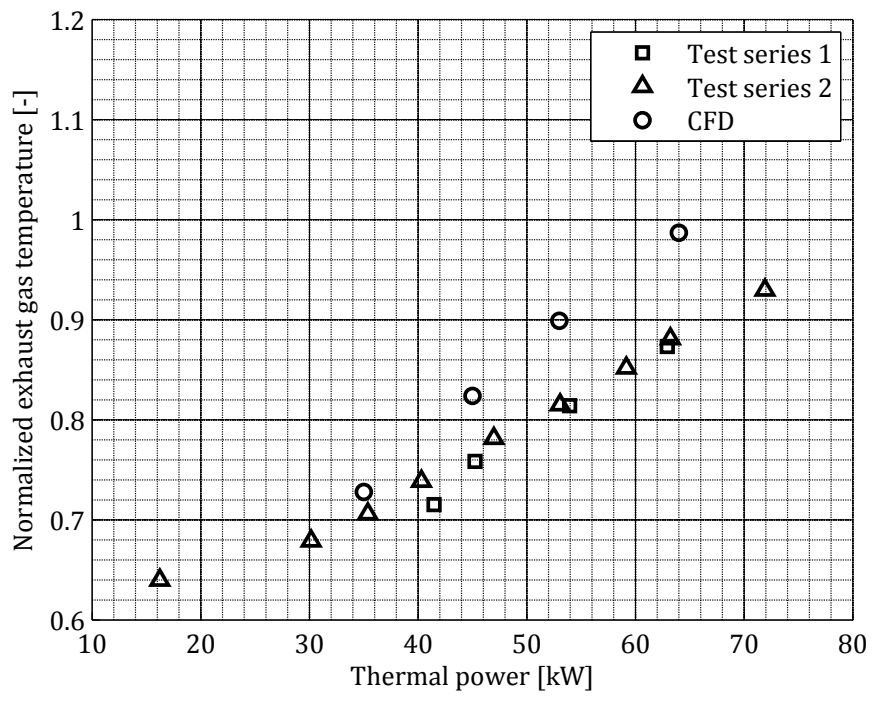

FIGURE 8: COMPARISON OF THE MEASURED AND CALCULATED NORMALIZED EXHAUST GAS TEMPERATURES AS FUNCTION OF THE THERMAL POWER.

trend line. The CFD result for the low power case shows good correspondence with the measured value. In the other cases, predicted temperatures are overpredicted significantly. The difference might be caused by an inaccurate prediction of the flow field near the sample location, but also by radiative losses from the thermocouples. A new test is planned with shielded thermocouples to evaluate possible measurement errors. High heat loss from the combustor to the environment during the tests is unlikely because of proper insulation.

The $\mathrm{CO}_{2}$ levels as function of the equivalence ratio (ER) in the primary zone are given in Fig. 9. The graph illustrates that there is a rather good agreement between the CFD and the test results. Due to an unclear reason, a remarkable jump in concentration is seen in the data from the second test series around an ER of 0.65 . From this point, the $\mathrm{CO}_{2}$ levels are more sensitive to the equivalence ratio. This behaviour is also observed in the $\mathrm{O}_{2}$ concentration graph shown in Fig. 10, though less pronounced.

Given the above comparisons of particularly the temperatures and $\mathrm{O}_{2}$ levels, the authors suspect that some fresh combustion air has been leaking through the connection between the liner and the exhaust duct (see Fig. 1). This could have diluted the product gases in front of the measurement location. A possible gap between these walls was expected to be small due to thermal expansion of the liner, but validation is needed to exclude any influence of air leakage here.

The normalized concentration of $\mathrm{CO}$ in the exhaust gases is plotted in Fig. 11. The graph shows the typical trend of $\mathrm{CO}$ levels as function of the equivalence ratio. Optimum combustion efficiency is found to occur around an ER of 0.55. Again, there

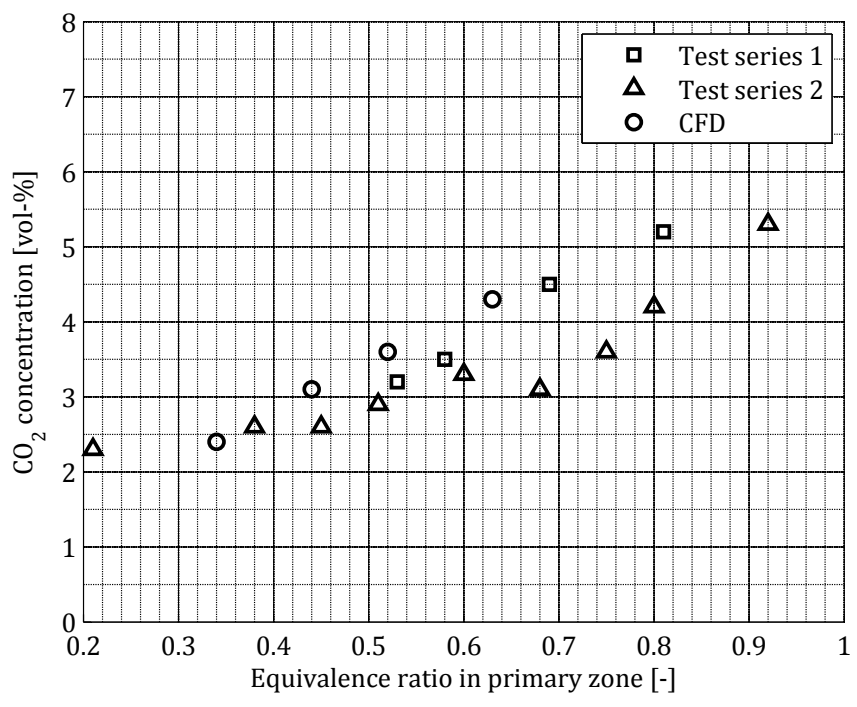

FIGURE 9: COMPARISON OF THE MEASURED AND CALCULATED $\mathrm{CO}_{2}$ CONCENTRATION AS FUNCTION OF THE EQUIVALENCE RATIO.

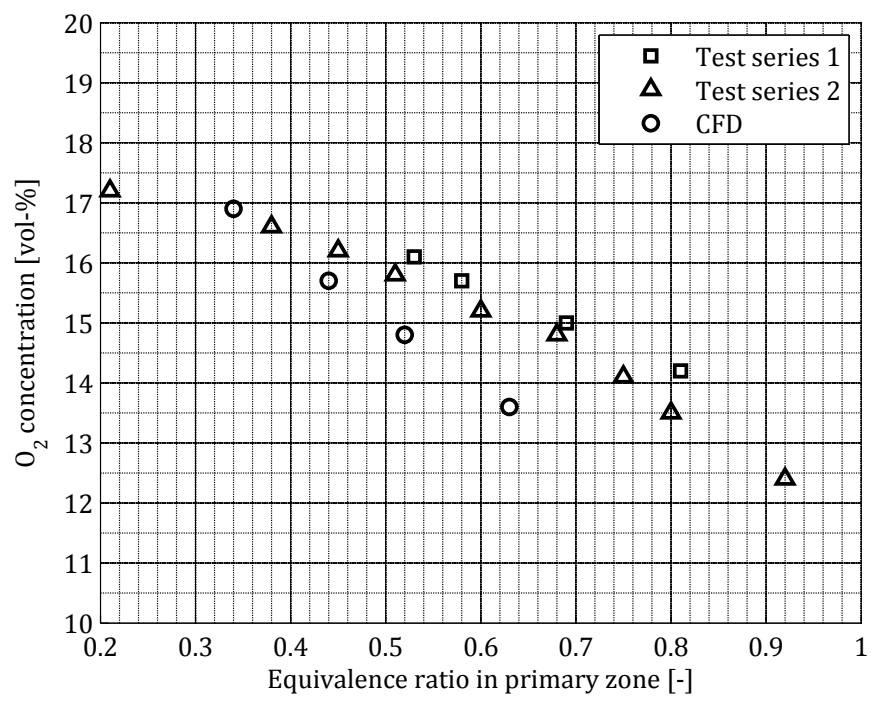

FIGURE 10: COMPARISON OF THE MEASURED AND CALCULATED $\mathrm{O}_{2}$ CONCENTRATION AS FUNCTION OF THE EQUIVALENCE RATIO.

is a discrepancy between the first data point from test series 1 and the general trend indicated by the other measurements. As suggested earlier, the startup procedure might have been too short to fully preheat the combustor. Relatively cool casing walls may have decreased the combustion air temperature, for which the $\mathrm{CO}$ levels are highly sensitive. 


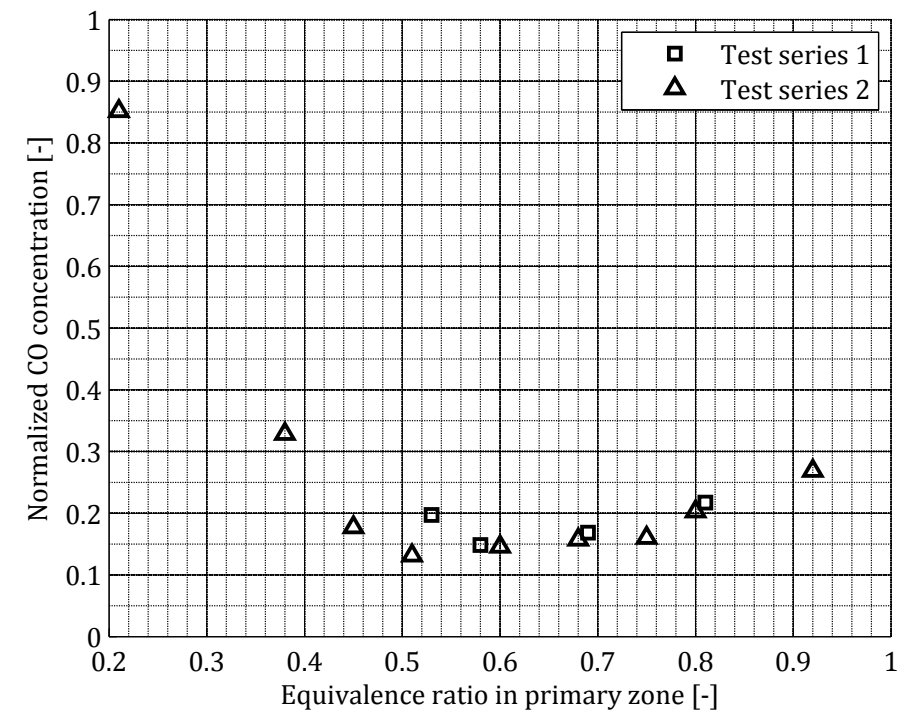

FIGURE 11: COMPARISON OF THE MEASURED AND CALCULATED NORMALIZED CO CONCENTRATION AS FUNCTION OF THE EQUIVALENCE RATIO.

$\mathrm{CO}$ emissions predicted by the CFD model are not shown in the graph because they were strongly underestimated over the entire range of operating conditions. Although the calculations show that $\mathrm{CO}$ is formed where combustion is in an early stage, almost all $\mathrm{CO}$ is consumed in subsequent reactions so that $\mathrm{CO}$ levels at the outlet are negligible. This deficiency is a consequence of the fast chemistry assumption behind the steady laminar flamelet model. The flame is assumed to immediately respond to the mixing state, and departure from chemical equilibrium is accounted for only as a result of aerodynamic strain. The strain rate near the exhaust is very low, so that insignificant $\mathrm{CO}$ levels are predicted at the sample location. Relatively slow chemical processes such as low-temperature $\mathrm{CO}$ oxidation cannot be described by the current combustion model. Models that include chemical non-equilibrium due to large chemical timescales, such as the unsteady flamelet model, should give more accurate results.

Figure 12 shows the relation between the normalized $\mathrm{NO}_{\mathrm{x}}$ emissions and exhaust gas temperatures. The graph confirms the expected increase in concentration with gas temperature. Since the fuel does not contain nitrogen, these emissions are due to the formation of thermal or prompt $\mathrm{NO}_{\mathrm{x}}$. Results from the CFD model are omitted as the model fails to predict reasonable $\mathrm{NO}_{\mathrm{x}}$ emission levels. The calculated concentrations are negligible, indicating that the predicted maximum flame temperatures are generally too low because oxides of nitrogen are formed at high temperatures. Another reason might be the formation of prompt $\mathrm{NO}_{\mathrm{x}}$ in pockets of fuel-rich air. This mechanism is not included in the model and therefore does not contribute to the results.

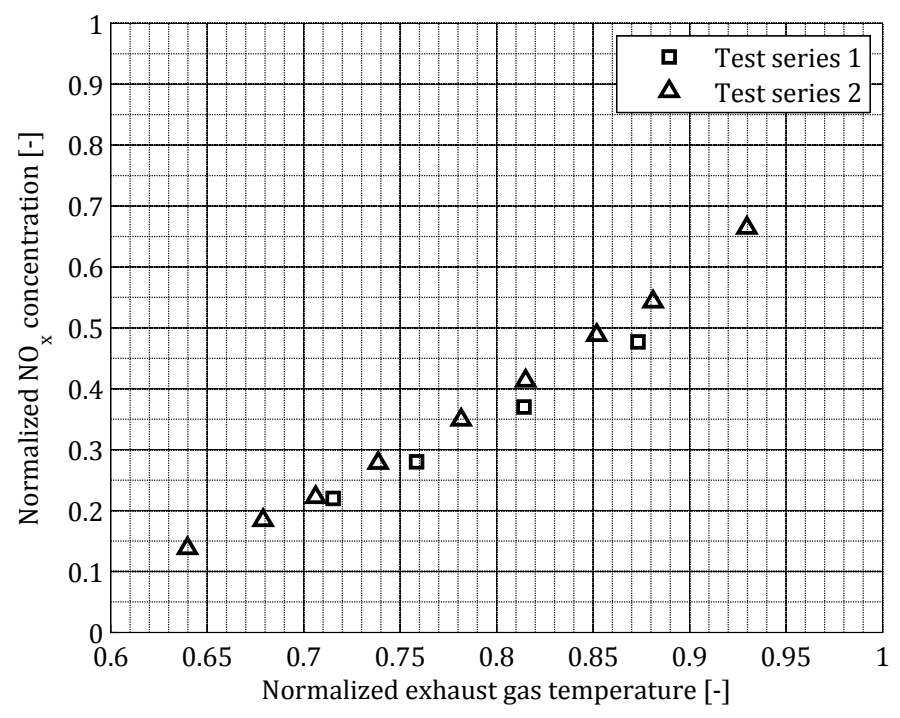

FIGURE 12: COMPARISON OF THE MEASURED AND CALCULATED NORMALIZED $\mathrm{NO}_{\mathrm{X}}$ CONCENTRATION AS FUNCTION OF THE NORMALIZED EXHAUST GAS TEMPERATURE.

Simulation of the fuel spray indicates that the evaporation rate of ethanol is quite low. This causes the larger droplets to eventually impinge on the liner surface and then vaporize instantly in accordance with the boundary condition prescribed at these walls. In order to get more insight into the evaporation process, the evolution of the droplet diameter as function of the vertical position is shown in Fig. 13. The graph reports tracking data for 9 different droplet diameters in the spray. It can be seen that droplets with an initial diameter larger than $60 \mu \mathrm{m}$ are not completely evaporated before reaching the wall, which is indicated by the dashed line. According to the cumulative droplet size distribution given in Fig. 5, this means that about $65 \%$ of the fuel is not vaporized in time.

Evaluation of droplet temperature data over time shows that the droplets are quickly heated up to a certain equilibrium temperature. At this temperature, the heat transfer towards the droplet is equal to the evaporative cooling. Since the diffusion coefficient is high in the hot combustor environment and the heat of vaporization of ethanol is relatively large, the droplet temperature does not reach boiling point. This finding is confirmed by experimental data found in Maqua et al. [18].

In Fig. 14, the square of the droplet diameter is shown as function of time. The graph illustrates a predominantly linear relation between these parameters, which means the evaporation process can be approximated using the $d^{2}$-law:

$$
d_{p}^{2}=d_{p, 0}^{2}-\lambda_{\mathrm{ev}} t
$$




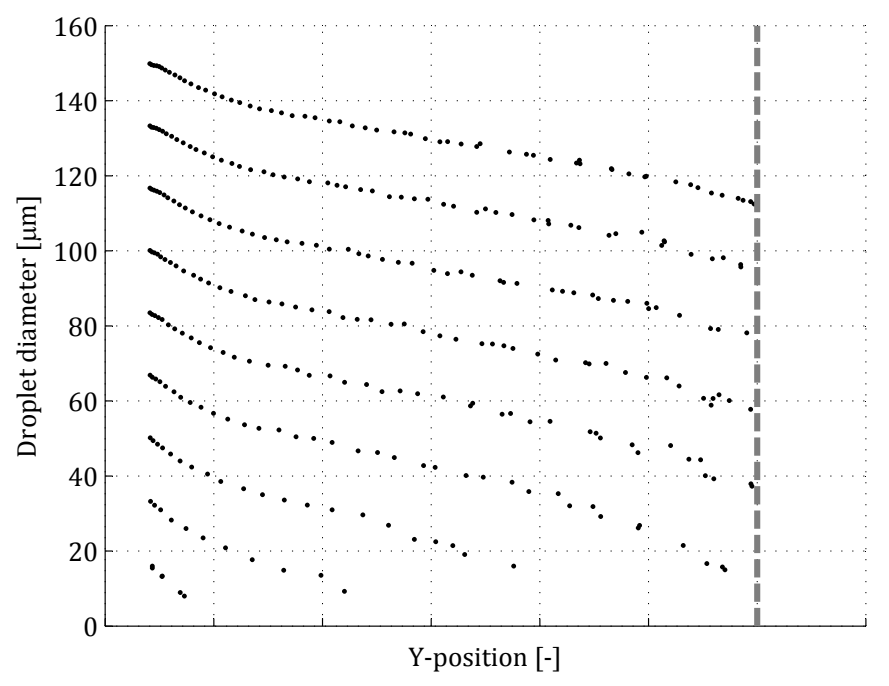

FIGURE 13: CALCULATED ETHANOL DROPLET DIAMETER AS FUNCTION OF VERTICAL POSITION IN THE BASE CASE. THE DASHED LINE INDICATES THE LINER.

where $d_{p, 0}^{2}$ is the initial droplet diameter, $t$ is the droplet residence time and $\lambda_{\mathrm{ev}}$ is the evaporation constant. The $d^{2}$-law is widely used to describe the evaporation of single component, spherical droplets. Evaporation constants for ethanol under flame conditions have been determined by Goldsmith [19]. Experiments with burning ethanol droplets in quiescent air showed that $\lambda_{\mathrm{ev}}$ is $8.6 \cdot 10^{-7} \mathrm{~m}^{2} / \mathrm{s}$. The evaporation constant in the current simulations can be determined from Fig. 14 and varies between $12 \cdot 10^{-7}$ and $17 \cdot 10^{-7} \mathrm{~m}^{2} / \mathrm{s}$ for the droplets larger than $50 \mu \mathrm{m}$. These values for $\lambda_{\mathrm{ev}}$ are somewhat higher than measured by Goldsmith, but higher evaporation constants in the CFD model are to be expected due to the effect of the ambient air temperature and velocity [19].

Unfortunately, no experimental data is available to clearly determine the volume occupied by the spray in practice. In an effort to verify the simulated droplet behaviour qualitatively, a photograph of the ethanol flame is shown in Fig. 15. The picture has been taken during the base case experiment via a mirror that was mounted behind the exhaust. In order to improve the visibility of the flame, Fig. 15a has been recolored to get Fig. 15b. The recolored picture has been obtained by amplifying the blue component of the RGB data and besides correcting this component for the white areas.

In the original picture, three bright spots can be observed at the inner liner surface. Two of these spots, indicated by the green arrows, are glowing constantly in time and suggest that the inner part of the liner does not have a uniform temperature. Particu-

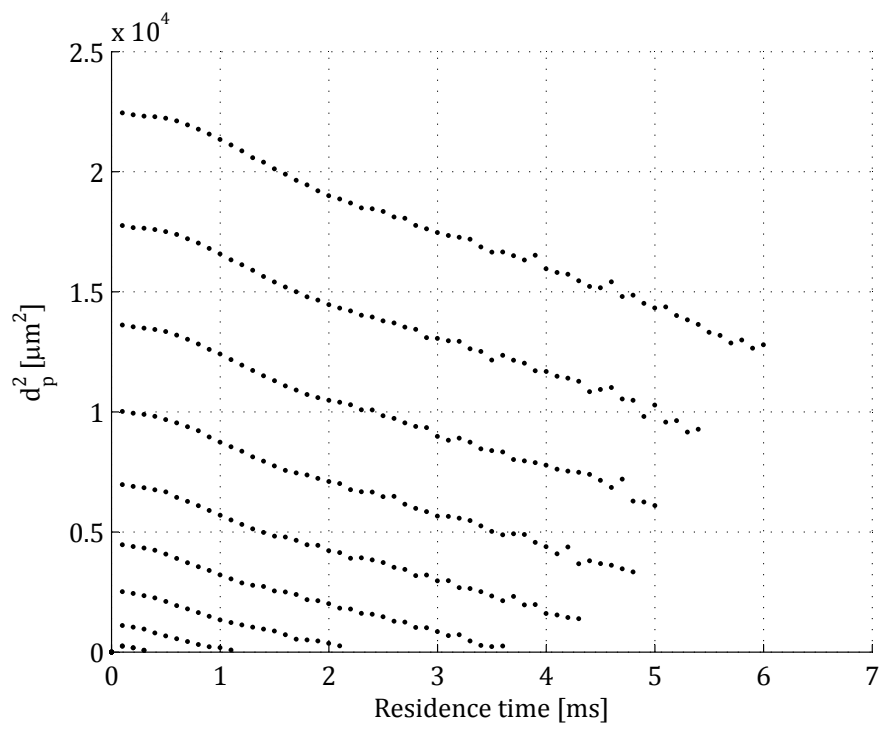

FIGURE 14: CALCULATED SQUARE DROPLET DIAMETER AS FUNCTION OF RESIDENCE TIME IN THE BASE CASE.

larly the white-colored zone closest to the nozzle demonstrates that very high surface temperatures must have been reached. The cause may be found in small, protruding edges of the different liner sections, which are fully surrounded by hot gases. This can also explain why the thermochromic paint at the outer surface did not indicate exceptionally high temperatures at these locations. The other bright spot, indicated by the red arrow, fluctuates at the same frequency as the blue colored flame close to the nozzle. When looking at the recolored image, it seems that the flame indeed reaches up to the liner. Still, the exact shape of the flame is not very clear, so additional research is required to be conclusive on this point.

\section{CONCLUSIONS}

In this work, combustion of ethanol has been studied in a modified OP16 industrial gas turbine combustor. Both combustion tests and CFD simulations have been performed with a thermal input ranging from 16 to $72 \mathrm{~kW}$. The measurements have been used to validate the accuracy of the CFD model.

Comparison of the numerical solutions with the experimental data shows a satisfactory agreement for the low power conditions. Considerable deviations are observed at the higher power conditions, for which the main reason is to be identified in upcoming combustion tests.

The CFD model proved to be unsuitable for the prediction of $\mathrm{CO}$ and $\mathrm{NO}_{\mathrm{x}}$ emissions. It is expected that the strong underestimation of $\mathrm{CO}$ concentrations in the exhaust gas is due to the 


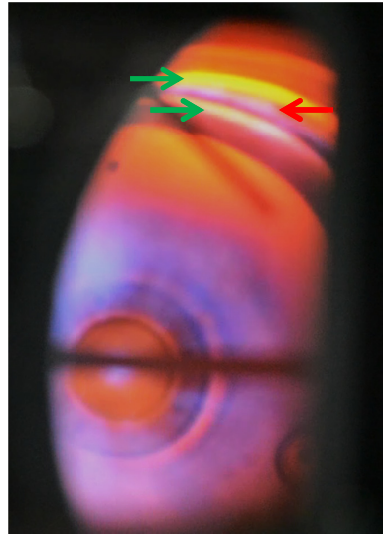

(a) Original

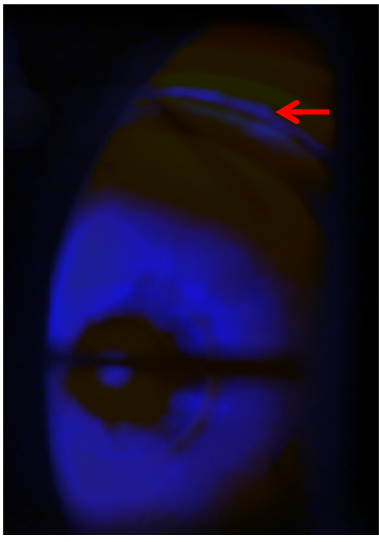

(b) Recolored
FIGURE 15: IMAGE OF THE ETHANOL FLAME TAKEN DURING COMBUSTION AT BASE CONDITIONS.

fast chemistry assumption. The steady laminar flamelet model is unable to capture slow chemistry and predicts equilibrium conditions at the outlet. Concerning the oxides of nitrogen, the inaccurate results are possibly caused by underprediction of the flame temperature and the lack of a prompt $\mathrm{NO}_{\mathrm{x}}$ mechanism in the model.

According to the simulations, about $65 \%$ of the fuel does not evaporate sufficiently fast and hence impacts on the liner surface. Predicted evaporation rates are found to be 40 to $100 \%$ higher than for burning ethanol droplets in quiescent air, but it is not clear whether the effects of convection and ambient air temperature are adequately modelled.

Future work includes improving the current CFD model with respect to the prediction of the pollutants $\mathrm{CO}$ and $\mathrm{NO}_{\mathrm{x}}$. This may be achieved by selecting a different combustion model and by including a model for the formation of prompt $\mathrm{NO}_{\mathrm{x}}$. Also, an additional combustion test will be performed in an effort to clarify the shape of the flame and the fuel spray.

\section{ACKNOWLEDGMENT}

The authors would like to thank the Province of Overijssel for sponsoring this work as part of the BE2.O program.

\section{REFERENCES}

[1] Fluent, 2006. Fluent 6.3 user's guide.

[2] Menter, F., 2012. "Two-equation eddy-viscosity turbulence models for engineering applications". AIAA journal, 32(8).

[3] Engdar, U., and Klingmann, J., 2002. "Investigation of two-equation turbulence models applied to a confined axissymmetric swirling flow". ASME.
[4] Cengel, Y., 2007. Heat and mass transfer: a practical approach. Boston: McGraw-Hill; 3rd ed.

[5] Merci, B., Roekaerts, D., and Sadiki, A., 2011. Experiments and numerical simulations of diluted spray turbulent combustion: proceedings of the 1st international workshop on turbulent spray combustion, Vol. 17. Springer.

[6] Faeth, G., Hsiang, L., and Wu, P., 1995. "Structure and breakup properties of sprays". International Journal of Multiphase Flow, 21, pp. 99-127.

[7] Moin, P., and Apte, S., 2006. "Large-eddy simulation of realistic gas turbine combustors". AIAA journal, 44(4), pp. 698-708.

[8] Elghobashi, S., 2006. "An updated classification map of particle-laden turbulent flows". In IUTAM Symposium on Computational Approaches to Multiphase Flow, Springer, pp. 3-10.

[9] Ranade, V., 2001. Computational flow modeling for chemical reactor engineering, Vol. 5. Academic press.

[10] Ashgriz, N., 2011. Handbook of Atomization and Sprays: Theory and Applications. Springer.

[11] Reid, R., Prausnitz, J., and Poling, B., 1987. "The properties of liquids and gases". McGraw-Hill, New York.

[12] Faeth, G., 1977. "Current status of droplet and liquid combustion”. Progress in Energy and Combustion Science, 3(4), pp. 191-224.

[13] Tseng, C., and Viskanta, R., 2005. "Effect of radiation absorption on fuel droplet evaporation". Combustion science and technology, 177(8), pp. 1511-1542.

[14] Lefebvre, A., Ballal, D., and Bahr, D., 2010. Gas turbine combustion: alternative fuels and emissions. CRC Press.

[15] Lefebvre, A., 1988. Atomization and sprays. CRC.

[16] Röhl, O., and Peters, N., 2009. "A reduced mechanism for ethanol oxidation". In European Combustion Meeting, Vienna, Austria, pp. 14-17.

[17] Lefebvre, A., 1984. "Flame radiation in gas turbine combustion chambers". International journal of heat and mass transfer, 27(9), pp. 1493-1510.

[18] Maqua, C., Castanet, G., Grisch, F., Lemoine, F., Kristyadi, T., and Sazhin, S., 2008. "Monodisperse droplet heating and evaporation: Experimental study and modelling". International Journal of Heat and Mass Transfer, 51(15), pp. 3932-3945.

[19] Goldsmith, M., 1955. The Burning of Single Drops of Fuel in Oxidizing Atmospheres. CIT theses. California Institute of Technology. 